\title{
Budget Impact Analysis of Vericiguat for the Treatment of Chronic Heart Failure with Reduced Ejection Fraction Following a Worsening Event
}

\author{
Adnan Alsumali · Dominik Lautsch · Rongzhe Liu • Dipen Patel • \\ Sakina Nanji · Laurence M. Djatche
}

Received: January 28, 2021 / Accepted: February 19, 2021 / Published online: April 16, 2021

(C) Merck Sharp \& Dohme Corp., a subsidiary of Merck \& Co., Inc., Kenilworth, N.J., U.S, Rongzhe Liu, Dipen Patel, Sakina Nanji 2021

\begin{abstract}
Introduction: In the USA, patients with chronic heart failure (HF) with reduced ejection fraction (HFrEF) following a worsening $\mathrm{HF}$ event (WHFE) have significantly increased healthcare resource use and medical costs. This analysis aimed to estimate the budget impact of vericiguat as an add-on therapy to guidelinedirected medical therapy (GDMT) for the treatment of chronic HFrEF following a WHFE from a US commercial payer perspective.

Methods: A model was developed to estimate the budget impact of adding vericiguat to the formulary by comparing a current scenario (GDMT) and a new scenario (vericiguat plus GDMT) to a hypothetical 10-million-member commercial payer over a 3-year time horizon. Epidemiology data was obtained from literature. Treatment utilization rates of GDMT and clinical inputs (HF hospitalization and
\end{abstract}

Supplementary Information The online version contains supplementary material available at https:// doi.org/10.1007/s12325-021-01681-2.

A. Alsumali $(\varangle) \cdot$ D. Lautsch · L. M. Djatche

Center for Observational and Real-World Evidence,

Merck \& Co, Inc, Kenilworth, NJ, USA

e-mail: adnan.alsumali@merck.com

R. Liu · D. Patel · S. Nanji

Pharmerit - an OPEN Health Company, Bethesda,

MD, USA cardiovascular $[\mathrm{CV}]$ morality) were based on the VICTORIA trial in which patients with chronic HFrEF following a WHFE were randomized to GDMT plus placebo or GDMT plus vericiguat. Costs (2020 US\$) included drug acquisition, hospitalization, routine care, and mortality.

Results: Approximately 20,510 prevalent cases in year 1 and 3109 annual incident cases in subsequent years were estimated to be eligible for treatment with vericiguat. At a utilization rate of $5 \%, 10 \%$, and $15 \%$ for vericiguat over years $1-3$, the per member per month (PMPM) budget impact was estimated to be $\$ 0.048$, $\$ 0.064$, and \$0.086, respectively, associated with 44, 32, and 30 fewer HF hospitalizations and 7,12 , and 18 fewer CV deaths, respectively. Reduction in HF hospitalizations and CV deaths reduced the budget impact by $14 \%$ in total over 3 years.

Conclusion: Adding vericiguat to commercial plan formulary was associated with limited budget impact, primarily driven by drug acquisition costs but partially offset by reduced cost of HF hospitalizations and CV deaths.

Keywords: Budget impact; Cost analysis; Heart failure with reduced ejection fraction; Vericiguat; Worsening heart failure 


\section{Key Summary Points}

From a US commercial payer perspective, this study estimated the budget impact of vericiguat as an add-on therapy to guideline-directed medical therapy for the treatment of chronic HFrEF following a worsening HF event by integrating information from the VICTORIA trial.

At a utilization rate of $5 \%, 10 \%$, and $15 \%$ for vericiguat over years 1-3, the per member per month budget impact was estimated to be $\$ 0.048, \$ 0.064$, and $\$ 0.086$, respectively.

Adding vericiguat to a US commercial plan formulary was associated with limited budget impact, primarily driven by drug acquisition costs but partially offset by reduced cost of HF hospitalizations and CV deaths.

\section{DIGITAL FEATURES}

This article is published with digital features, including a summary slide, to facilitate understanding of the article. To view digital features for this article go to https://doi.org/10.6084/ m9.figshare.14054147.

\section{INTRODUCTION}

Heart failure (HF) is a common disease of societal importance in the USA with a projected prevalence of 8 million adults by the year 2030 [1]. Approximately $31-56 \%$ of patients with HF have reduced ejection fraction (HFrEF), defined as a left ventricular ejection fraction (LVEF) of $40 \%$ or less [2-7]. Patients with HF may experience multiple worsening HF event (WHFE) (i.e., hospitalization for $\mathrm{HF}$ or initiation of intravenous diuretic therapy in the outpatient setting) despite the use of standard guidelinedirected medical therapies (GDMT) [8, 9].
Importantly, each event places patients at increased risk of additional events [10, 11].

Approximately $30 \%$ of patients with chronic HFrEF experience at least one WHFE in the first year upon diagnosis $[12,13]$. These WHFE have an impact on the patients' prognoses and are further associated with a considerable economic burden to payers and patients likewise. The 2-year mortality rate in patients with HFrEF who experienced a WHFE was estimated at 23\% $[11,14]$. These patients are at even higher risk of mortality after each subsequent HF hospitalization $[15,16]$.

The direct medical costs of HF in the USA are projected to increase from $\$ 20.9$ billion in 2012 to $\$ 53.1$ billion in 2030 primarily due to medical cost inflation, followed by increase of US population size [17]. Inpatient hospitalization costs are the primary driver of total costs in HF [17-20], and patients with HFrEF who experience a WHFE are at high risk for recurrent HFrelated hospitalizations [11]. Medical resource use and costs are also significantly higher for patients with chronic HFrEF following a WHFE compared to patients with stable chronic HFrEF $[20,21]$, so further treatment options are needed in this population.

Vericiguat, a novel soluble guanylate cyclase stimulator, was filed for approval with the US Food and Drug Administration (FDA) in 2020 for the treatment of adult patients with chronic HF and LVEF of less than $45 \%$ following a WHFE. The filing was based on findings of pivotal trial VICTORIA (NCT02861534), a phase 3, randomized, double-blind clinical trial which compared efficacy and safety between vericiguat plus GDMT and placebo plus GDMT [8].

Given the economic burden of patients with chronic HFrEF following a WHFE, a budget impact analysis was conducted to understand the total direct medical cost trade-off associated with adding vericiguat on top of GDMT in this population in a hypothetical commercial health plan in the USA. 


\section{METHODS}

\section{Model Overview}

A model was developed to assess the budget impact of adding vericiguat as an add-on therapy to GDMT for the treatment of chronic HFrEF following a WHFE. The analysis was conducted from a US commercial health plan perspective over a 3-year time horizon.

To estimate the budget impact of vericiguat, total costs from two scenarios were compared: the current market scenario without vericiguat (i.e., GDMT alone) and a new market scenario with vericiguat as an add-on therapy to GDMT (Fig. 1). All cost inputs were inflated to 2020 US dollars using the medical care component of the Consumer Price Index [22].

This study relied on published estimates from literature as analysis inputs. Therefore, ethics committee approval was not required.

\section{Population}

The target eligible population was defined as adult patients with chronic HFrEF $($ LVEF <
45\%) following a WHFE, in line with the VICTORIA trial population [8]. An eligible population size was estimated for a hypothetical US commercial health plan with 10 million members.

To estimate the eligible population over the model time horizon, the model included prevalent cases entering the model at year 1 and annual incident cases entering the model at year 2 and year 3. Epidemiologic inputs from published literature were used to estimate prevalent and incident cases (Table 1).

For simplicity, it was assumed that the eligible population estimated in specific year would enter the model in the beginning of that year and be followed until death. After the first model year, the total patient population in each year consisted of a mix of (1) newly eligible patients that entered the model in the current year and (2) patients that became eligible and entered the model in the past year(s) and remained alive in the current year.

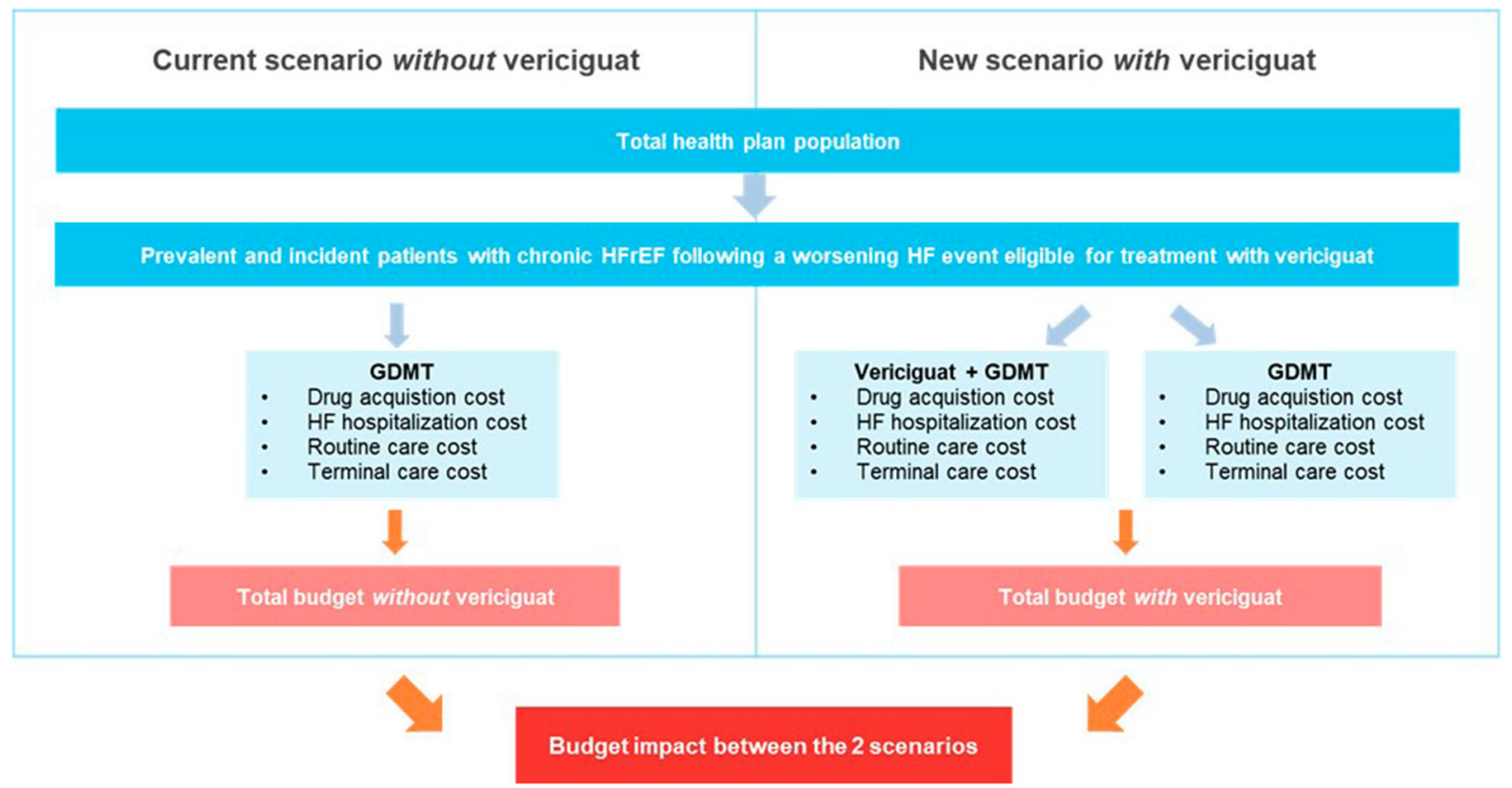

Fig. 1 Budget impact model structure. GDMT guideline-directed medical therapy, $H F$ heart failure, $H F r E F$ heart failure with reduced ejection fraction 
Table 1 Population inputs and estimation

\begin{tabular}{llc}
\hline Parameter & Value, \% & Estimated population, $n$ \\
\hline Prevalence at year 1 & & \\
Prevalence of HF [8,33] & $1.3^{\mathrm{a}}$ & 131,950 \\
Proportion with ejection fraction $<45 \%[2,34]$ & 58.0 & 76,531 \\
Proportion with WHFE [35] & 26.8 & 20,510 \\
Annual incidence at year 2 and year 3 & & \\
Incidence of HF [33] & 0.2 & 20,000 \\
Proportion with ejection fraction $<45 \%[2,34]$ & 58.0 & 11,600 \\
Proportion with WHFE [35] & 26.8 & 3109 \\
\hline
\end{tabular}

$H F$ heart failure, WHFE worsening heart failure event

${ }^{a}$ Estimated as prevalence of men (1.2\%) and prevalence of women (1.7\%) [33], weighted by sex ratio (23.9\% female, $76.1 \%$ male) [8]

\section{Treatment Utilization}

To estimate the number of patients treated with specific treatments in market scenarios with and without vericiguat, utilization rates of each individual drug were applied to the estimated eligible patients newly entering the model in each year.

In the current market scenario without vericiguat, all eligible patients were treated with a mix of GDMT drugs, including angiotensinconverting enzyme inhibitor (ACEi) or angiotensin receptor blocker (ARB), beta blockers (BB), sacubitril/valsartan, and mineralocorticoid receptor antagonist (MRA). The treatment utilization rates of each individual GDMT drug were based on VICTORIA trial data $(73.4 \%$ for ACEi or ARB, $93.1 \%$ for BB, $14.5 \%$ for sacubitril/valsartan, and $70.3 \%$ for MRA [8]) and assumed to be constant over time.

In the new market scenario with vericiguat, it was assumed that a proportion of patients would receive vericiguat as add-on therapy to GDMT. We assumed GDMT to remain as is after the introduction of vericiguat and solely calculated add-on utilization versus no add-on, assuming an incremental increase of $5 \%$ in vericiguat utilization rate every year (i.e., $5 \%$ in year $1,10 \%$ in year 2 , and $15 \%$ in year 3 ).

\section{Clinical Inputs}

The clinical inputs of first HF hospitalization and CV mortality were based on the primary composite outcome in the VICTORIA trial $[8,23]$ (Table 2). The number of HF hospitalization and $\mathrm{CV}$ mortality events were estimated from the primary composite outcome (combining first HF hospitalization or CV mortality) in the following four steps and estimated separately for patients treated with vericiguat plus GDMT and GDMT alone.

First, the rates of the primary composite outcome (combining first HF hospitalization or CV mortality) from the VICTORIA trial were converted into the cumulative probability of the composite outcome over time. It was assumed that the outcome rates observed within the trial period (with a median follow-up of 10.8 months) would be constant over time throughout the model time horizon (Table 2).

Second, the cumulative proportion of patients experiencing the composite outcome was further partitioned into the cumulative proportions of patients experiencing first HF hospitalization and CV mortality separately, based on the distribution of CV mortality and HF hospitalization events that contributed to the composite outcome observed in VICTORIA (Table 2). 
Table 2 Clinical inputs

\begin{tabular}{lcc}
\hline Parameter & Vericiguat + GDMT & $\begin{array}{c}\text { GDMT } \\
\text { alone }\end{array}$ \\
\hline $\begin{array}{l}\text { Rate (events per } 100 \text { patient-years) of primary composite outcome of first HF } \\
\text { hospitalization and CV mortality }\end{array}$ & $33.6^{\mathrm{a}}$ & $37.8^{\mathrm{a}}$ \\
Estimated cumulative proportion of patients experiencing composite outcome at end of year & $28.5 \%$ & $31.5 \%$ \\
Year 1 & $48.9 \%$ & $53.0 \%$ \\
Year 2 & $63.5 \%$ & $67.8 \%$ \\
Year 3 & & \\
Breakdown of primary composite outcome & $77.0 \%^{\mathrm{a}}$ & $76.9 \%^{\mathrm{a}}$ \\
Proportion of first HF hospitalization & $23.0 \%^{\mathrm{a}}$ & $23.1 \%^{\mathrm{a}}$ \\
Proportion of CV mortality & & \\
Estimated cumulative proportion of patients experiencing first HF hospitalization at end of year & $22.0 \%$ & $40.8 \%$ \\
Year 1 & $37.7 \%$ & $52.1 \%$ \\
Year 2 & $48.9 \%$ &
\end{tabular}

Estimated cumulative proportion of patients experiencing CV mortality at end of year

$\begin{array}{lll}\text { Year } 1 & 6.6 \% & 7.3 \% \\ \text { Year } 2 & 11.1 \% & 12.3 \% \\ \text { Year } 3 & 14.6 \% & 15.7 \% \\ \text { Proportion of patients ever experiencing first HF hospitalization who further } & 77.0 \%^{\mathrm{a}} & 78.8 \%^{\mathrm{a}}\end{array}$
experienced subsequent HF hospitalization

Estimated cumulative proportion of patients experiencing subsequent HF hospitalization at end of year

\begin{tabular}{lll} 
Year 1 & $16.9 \%$ & $19.1 \%$ \\
Year 2 & $29.0 \%$ & $32.1 \%$ \\
Year 3 & $37.7 \%$ & $41.1 \%$ \\
\hline
\end{tabular}

$C V$ cardiovascular, GDMT guideline-directed medical therapy, $H F$ heart failure

${ }^{\text {a }}$ Armstrong et al. [8]

Third, subsequent HF hospitalizations were estimated by multiplying the cumulative proportion of first HF hospitalization by the proportion of patients ever experiencing first HF hospitalization who further experienced subsequent HF hospitalization. It was assumed that subsequent HF hospitalization proportion may occur in the same year as the first HF hospitalization (Table 2).
Finally, the cumulative proportion of patients experiencing first and subsequent HF hospitalizations and the cumulative proportion of CV mortality were applied to the eligible population that newly entered the model in each year to derive the cumulative number of HF hospitalization and CV mortality events over time.

Our budget impact model was based on CV mortality given the relatively short time 
horizon and the fact that there was no statistically significant difference in non-CV mortality between the vericiguat plus GDMT arm and placebo plus GDMT arm in VICTORIA [8]. In addition, we assumed no differences in adverse events between the two scenarios, as there was no significant difference in safety profiles between the vericiguat plus GDMT arm and placebo plus GDMT arm in VICTORIA [8].

\section{Drug Costs}

Daily drug acquisition costs for vericiguat and each individual GDMT (Table 3) were calculated as the product of the cost per tablet and number of tablets per day for each drug [Table S1]. Target doses of GDMT drugs and vericiguat were obtained from the products' prescribing information and the VICTORIA trial, respectively. Drug wholesale acquisition costs (WAC) and package information for GDMT drugs were obtained from RED BOOK [24]. It was assumed that patients would initiate treatment upon model entry and continue until death (based on CV mortality), in line with drug prescribing information, where no discontinuation rule was specified [25-28].

For drug costing purposes, half-cycle corrections were applied to avoid overestimation or underestimation of drug costs. For example, if $90 \%$ of patients were estimated to be on treatment at the end of year 1 and $80 \%$ estimated at the end of year 2 , then the costing of drug acquisition in year 2 would be based on $85 \%$, the average of $90 \%$ and $80 \%$.

\section{Medical Costs}

Costs of HF hospitalization in each year were estimated by multiplying the cost per hospitalization event (Table 3 ) by the number of HF hospitalizations occurring in that year. Costs of routine care in each year were estimated by assigning monthly routine care costs (Table 3 ) to the number of patients remaining alive in that year. Half-cycle corrections were applied to avoid overestimation or underestimation of routine care costs. Costs of terminal care in each year were estimated by multiplying a one-time terminal care cost (based on published direct HF-related medical costs in the last 1 month

Table 3 Cost inputs

\begin{tabular}{|c|c|c|}
\hline Parameter & Value & References \\
\hline \multicolumn{3}{|l|}{ Drug costs per day ${ }^{a}$} \\
\hline Vericiguat & $\$ 19.43$ & [24] \\
\hline ACEi or $\mathrm{ARB}$ & $\$ 0.03$ & {$[24,25]$} \\
\hline Beta blockers & $\$ 0.05$ & {$[24,26]$} \\
\hline Sacubitril/valsartan & $\$ 19.43$ & {$[24,27]$} \\
\hline MRA & $\$ 0.11$ & {$[24,28]$} \\
\hline \multicolumn{3}{|l|}{ Medical costs } \\
\hline HF hospitalization costs (per event) & $\$ 23,605$ & {$[20,22]$} \\
\hline Routine care cost (per month alive) & $\$ 307$ & {$[20,22]$} \\
\hline Terminal care cost (per mortality event) ${ }^{\mathrm{b}}$ & $\$ 31,779$ & {$[22,36]$} \\
\hline
\end{tabular}


before death) (Table 3) by the number of CV deaths in that year.

\section{Model Outputs}

The primary model output was the budget impact of vericiguat. The total budget impact was estimated on an annual basis as the difference in total costs between the market scenarios with and without vericiguat for the total 10-million-member health plan population in aggregate. The total costs in both market scenarios in each year were estimated as the sum of total costs of drug acquisition, HF hospitalization, routine care, and terminal care incurred in that year.

In addition to total budget impact, as is standard with US commercial payers, the budget impact per member per month (PMPM), per member per year (PMPY), per patient per month (PPPM), and per patient per year (PPPY) were estimated.

The secondary model outputs were the total number of HF hospitalization events avoided and the total number of $\mathrm{CV}$ deaths avoided due to introduction of vericiguat, which were estimated as the difference in total number of events between the market scenarios with and without vericiguat for the total plan population on an annual basis.

\section{Scenario Analyses}

To assess the impact of uncertainty of model inputs and assumptions [Table S2] on model results, deterministic scenario analyses were conducted for the overall eligible population, in which one parameter was varied at a time while holding the other parameters unchanged. Parameters examined in scenario analyses included daily drug acquisition cost (including potential drug cost discount), medical cost inputs, and projected utilization rate of vericiguat (Table 5).

\section{RESULTS}

\section{Base Case}

In a hypothetical 10-million-member commercial health plan, approximately 20,510 prevalent HFrEF cases were estimated to be eligible for treatment with vericiguat in year 1 ; approximately 3109 annual incident cases were estimated for subsequent years. At a projected vericiguat utilization rate of 5\% (year 1), 10\% (year 2), and $15 \%$ (year 3), the budget impact was estimated to be $\$ 0.048$ PMPM $(\$ 5,764,274$ in total) in year 1, \$0.064 PMPM $(\$ 7,645,376$ in total) in year 2 , and $\$ 0.086$ PMPM $(\$ 10,326,041$ in total) in year 3 (Table 4) from the perspective of a health plan, driven by the higher annual cost per patient treated with vericiguat plus GDMT $(\$ 21,116$ averaged over 3 years since treatment initiation, compared to $\$ 15,404$ per patient treated with GDMT alone).

In addition, vericiguat was associated with a reduction of $44 \mathrm{HF}$ hospitalizations and $7 \mathrm{CV}$ deaths in year 1 , and a reduction of 32 HF hospitalizations and $12 \mathrm{CV}$ deaths in year 2 (Table 4). In total, 30 HF hospitalizations and 18 $\mathrm{CV}$ deaths were avoided over 3 years following introduction of vericiguat.

The reductions in HF hospitalizations and CV deaths reduced the budget impact by $9 \%$ and $4 \%$, respectively, over a 3 -year period.

\section{Sensitivity Analyses}

In the overall eligible population, decreasing the daily drug acquisition costs of both vericiguat and sacubitril/valsartan by $10 \%$ and $25 \%$ was associated with a PMPM impact of $\$ 0.058$ and $\$ 0.047$, respectively, averaged across 3 years, in comparison with $\$ 0.066$ in the base case (Table 5).

Increasing and decreasing HF hospitalization costs by $15 \%$ were associated with a PMPM impact of $\$ 0.065$ and $\$ 0.067$, respectively. In comparison with HF hospitalization cost, varying routine care cost or terminal care cost had relatively limited impact on the PMPM results (Table 5). 
Table 4 Base case analysis results

\begin{tabular}{|c|c|c|c|}
\hline & Year 1 & Year 2 & Year 3 \\
\hline \multicolumn{4}{|l|}{ Total costs } \\
\hline Without vericiguat & $\$ 351,207,596$ & $\$ 365,045,892$ & $\$ 385,313,354$ \\
\hline Drug acquisition & $\$ 21,390,120$ & $\$ 23,269,360$ & $\$ 25,371,024$ \\
\hline HF hospitalization & $\$ 209,462,276$ & $\$ 175,278,674$ & $\$ 151,855,028$ \\
\hline Routine care & $\$ 72,863,504$ & $\$ 79,264,965$ & $\$ 86,424,091$ \\
\hline Terminal care & $\$ 47,491,696$ & $\$ 87,232,893$ & $\$ 121,663,211$ \\
\hline With vericiguat & $\$ 356,971,870$ & $\$ 372,682,039$ & $\$ 395,639,395$ \\
\hline Drug acquisition & $\$ 28,433,582$ & $\$ 32,044,875$ & $\$ 36,937,022$ \\
\hline HF hospitalization & $\$ 208,407,967$ & $\$ 174,513,465$ & $\$ 151,133,033$ \\
\hline Routine care & $\$ 72,877,352$ & $\$ 79,302,706$ & $\$ 86,481,352$ \\
\hline Terminal care & $\$ 47,252,969$ & $\$ 86,820,993$ & $\$ 121,087,988$ \\
\hline Total budget impact & $\$ 5764,274$ & $\$ 7636,147$ & $\$ 10,326,041$ \\
\hline Drug acquisition & $\$ 7043,461$ & $\$ 8,775,515$ & $\$ 11,565,999$ \\
\hline HF hospitalization & $-\$ 1054,309$ & $-\$ 765,210$ & $-\$ 721,996$ \\
\hline Routine care $^{a}$ & $\$ 13,848$ & $\$ 37,742$ & $\$ 57,261$ \\
\hline Terminal care & $-\$ 238,727$ & $-\$ 411,900$ & $-\$ 575,223$ \\
\hline \multicolumn{4}{|c|}{ Other budget impact measures } \\
\hline PMPM & $\$ 0.048$ & $\$ 0.064$ & $\$ 0.086$ \\
\hline PMPY & $\$ 0.576$ & $\$ 0.764$ & $\$ 1.033$ \\
\hline PPPM & $\$ 23$ & $\$ 27$ & $\$ 32$ \\
\hline PPPY & $\$ 281$ & $\$ 323$ & $\$ 386$ \\
\hline \multicolumn{4}{|l|}{ Total number of events } \\
\hline \multicolumn{4}{|l|}{ Without vericiguat } \\
\hline HF hospitalization & 8874 & 7426 & 6433 \\
\hline CV mortality & 1494 & 2745 & 3828 \\
\hline \multicolumn{4}{|l|}{ With vericiguat } \\
\hline HF hospitalization & 8829 & 7393 & 6403 \\
\hline CV mortality & 1487 & 2732 & 3810 \\
\hline \multicolumn{4}{|c|}{ Number of events avoided ${ }^{b}$} \\
\hline HF hospitalization & 44 & 32 & 30 \\
\hline
\end{tabular}


Table 4 continued

\begin{tabular}{|c|c|c|c|}
\hline & Year 1 & Year 2 & Year 3 \\
\hline CV mortality & 7 & 12 & 18 \\
\hline
\end{tabular}

Increasing the utilization rate of vericiguat to $10 \%, 20 \%$, and $30 \%$, over year 1 to year 3 increased average PMPM to $\$ 0.132$ but also increased the average number of HF hospitalizations avoided and CV deaths avoided to 71 and 25, respectively, in comparison with $35 \mathrm{HF}$ hospitalization avoided and $12 \mathrm{CV}$ deaths avoided in base case (Table 5). Decreasing the utilization rate of vericiguat to $2.5 \%, 5 \%$, and $7.5 \%$ over year 1 to year 3 decreased PMPM to $\$ 0.033$ but also decreased the number of HF hospitalizations avoided and $\mathrm{CV}$ deaths avoided to 17 and 6 , respectively (Table 5).

\section{DISCUSSION}

Patients with chronic HFrEF following a WHFE are associated with significantly higher clinical and economic burden, compared with patients with stable chronic HFrEF, despite the use of standard GDMT [20, 21], which suggests an unmet need of treatment strategies for these patients. Recently, the VICTORIA trial has demonstrated the clinical benefit of vericiguat, a novel therapy, by showing that patients treated with vericiguat plus GDMT had lower number of HF hospitalizations and CV deaths compared to patients treated with GDMT alone [8]. Given the disease burden and the anticipated introduction of vericiguat in the USA, in addition to the clinical benefit on a patient level, it is also important for payers to understand the economic implications to the entire health plan population in which some eligible patients would be treated with vericiguat plus GDMT following the introduction of vericiguat, whereas the other eligible patients would be treated with GDMT alone. Given the above and also following the recommendation by the International Society for Pharmacoeconomics and Outcomes Research [29], this study was conducted to assess the budget impact of adding vericiguat to the formulary from a commercial payer perspective to help payers in making reimbursement decisions.

This study indicates that adding vericiguat to GDMT in an overall eligible worsening HF patient population would lead to small budget impacts of \$0.048 PMPM in year 1 and \$0.086 PMPM in year 3 from a US commercial payer perspective. This analysis also indicates that vericiguat would lead to 44 fewer HF hospitalizations and 7 fewer $\mathrm{CV}$ deaths in the first year and 106 fewer HF hospitalizations and 37 fewer $\mathrm{CV}$ deaths in total over 3 years following the introduction of vericiguat. The increase in drug acquisition costs with vericiguat was partially offset by the reduction in costs of HF hospitalizations and $\mathrm{CV}$ deaths due to clinical benefits of vericiguat.

Scenario analyses in which medical cost inputs were varied showed that the budget impact would be lower in the case of higher HF hospitalization cost and higher terminal care cost inputs, driven by the lower number of HF hospitalizations and $\mathrm{CV}$ deaths in patients treated with vericiguat. Compared to HF hospitalization cost inputs, varying terminal care cost and terminal care cost inputs had more limited effect on the budget impact. Varying the utilization rate of vericiguat would proportionally increase the budget impact but also proportionally increase the numbers of $\mathrm{HF}$ hospitalizations and CV deaths avoided. 
Table 5 Scenario analysis results averaged across 3 years

\begin{tabular}{|c|c|c|c|c|c|}
\hline Parameter & $\begin{array}{l}\text { Base case } \\
\text { setting }\end{array}$ & $\begin{array}{l}\text { Scenario } \\
\text { analysis } \\
\text { setting }\end{array}$ & $\begin{array}{l}\text { Budget } \\
\text { impact } \\
\text { PMPM, \$ }\end{array}$ & $\begin{array}{l}\text { Number of HF } \\
\text { hospitalizations } \\
\text { avoided }{ }^{\text {a }}\end{array}$ & $\begin{array}{l}\text { Number of CV } \\
\text { deaths } \\
\text { avoided }^{\text {a }}\end{array}$ \\
\hline Base case & & & 0.066 & 35 & 12 \\
\hline \multirow[t]{3}{*}{$\begin{array}{l}\text { Daily drug acquisition cost of } \\
\text { both vericiguat and } \\
\text { sacubitril/valsartan }\end{array}$} & $\$ 19.43$ & $\begin{array}{l}10 \% \\
\text { discount } \\
(\$ 17.49)\end{array}$ & 0.058 & 35 & 12 \\
\hline & & $\begin{array}{l}20 \% \\
\text { discount } \\
(\$ 15.54)\end{array}$ & 0.051 & 35 & 12 \\
\hline & & $\begin{array}{l}25 \% \\
\text { discount } \\
(\$ 14.57)\end{array}$ & 0.047 & 35 & 12 \\
\hline \multirow[t]{2}{*}{ HF hospitalization costs per event } & $\$ 23,605$ & $\begin{array}{l}15 \% \\
\text { increase } \\
(\$ 27,146)\end{array}$ & 0.065 & 35 & 12 \\
\hline & & $\begin{array}{l}15 \% \\
\quad \text { decrease } \\
(\$ 20,064)\end{array}$ & 0.067 & 35 & 12 \\
\hline \multirow[t]{2}{*}{ Routine care cost per month alive } & $\$ 307$ & $\begin{array}{l}15 \% \\
\text { increase } \\
(\$ 353)\end{array}$ & 0.066 & 35 & 12 \\
\hline & & $\begin{array}{l}15 \% \\
\quad \text { decrease } \\
(\$ 261)\end{array}$ & 0.066 & 35 & 12 \\
\hline \multirow[t]{2}{*}{$\begin{array}{l}\text { Terminal care cost per mortality } \\
\text { event }\end{array}$} & $\$ 31,779$ & $\begin{array}{l}15 \% \\
\text { increase } \\
(\$ 36,546)\end{array}$ & 0.065 & 35 & 12 \\
\hline & & $\begin{array}{l}15 \% \\
\quad \text { decrease } \\
(\$ 27,012)\end{array}$ & 0.066 & 35 & 12 \\
\hline \multirow[t]{2}{*}{$\begin{array}{l}\text { Projected utilization rate of } \\
\text { vericiguat }\end{array}$} & $\begin{array}{c}5 \%, 10 \%, 15 \% \\
\text { over years } 1\end{array}$ & $\begin{array}{c}10 \%, 20 \%, \\
30 \%\end{array}$ & 0.132 & 71 & 25 \\
\hline & to 3 & $\begin{array}{c}2.5 \%, 5 \% \\
7.5 \%\end{array}$ & 0.033 & 17 & 6 \\
\hline
\end{tabular}

$C V$ cardiovascular, $H F$ heart failure, $P M P M$ per member per month

a The number of events avoided were rounded down to be conservative 
To our knowledge, this is the first budget impact analysis that was conducted specifically in US patients with HFrEF following a WHFE. In addition, prior studies in HFrEF were conducted among patients with slightly different patient profile and clinical characteristics (e.g., New York Heart Association classification II-IV, LVEF of lower than 40\%) [30-32]. Although this study indicates limited budget impact for vericiguat, further cost-effectiveness analysis is warranted to provide a comprehensive assessment of the long-term clinical and economic implications of adding vericiguat to a commercial health plan in the US healthcare system.

As with all modeling analysis, this analysis has limitations which should be considered when interpreting the results. First, considering that all costs are dependent on clinical outcomes, results of this analysis based on VICTORIA populations may not be generalizable to real-world patient populations with a potentially different patient profile (e.g., prior WHFE or age) or potentially different treatment patterns (e.g., utilization rates of specific GDMT, treatment adherence). Second, given that the budget impact analysis results relied on the projected utilization rate of vericiguat, as shown by the results of scenario analyses, our analysis results may not be generalizable to populations with different adoption rates of vericiguat. Finally, this analysis relied on WAC for drug acquisition costs without accounting for realworld reimbursement mechanisms (e.g., coinsurance, rebate), which typically are not publicly available and vary substantially by health plan. To mitigate these limitations, scenario analyses were conducted by varying the projected utilization rates of vericiguat and the drug acquisition cost for both vericiguat and sacubitril/valsartan. Vericiguat received FDA approval in January 2021. Therefore, any uptakes built into this model are hypothetical as is usually the case with models. However, it will be interesting to understand the utilization of vericiguat over the upcoming years and update our budget impact analysis with recent realworld data once they become available.

\section{CONCLUSIONS}

Adding vericiguat to a commercial plan formulary as an add-on therapy for treatment of patients with HFrEF following a WHFE was associated a limited budget impact with a PMPM of less than 10 cents.

\section{ACKNOWLEDGEMENTS}

The authors thank the patients, along with their families and caregivers, who participated in the VICTORIA trial, from which the clinical inputs of this study were obtained.

Funding. This study and the journal's rapid service fee were funded by Merck Sharp \& Dohme Corp., a subsidiary of Merck \& Co., Inc., Kenilworth, NJ, USA.

Authorship. All named authors meet the International Committee of Medical Journal Editors (ICMJE) criteria for authorship for this article, take responsibility for the integrity of the work as a whole, and have given their approval for this version to be published.

Medical Writing, Editorial, and Other Assistance. Editorial assistance was provided by Catherine Mirvis, an employee of Pharmerit - an OPEN Health Company, Bethesda, MD, USA. The assistance was funded by Merck Sharp \& Dohme Corp., a subsidiary of Merck \& Co., Inc., Kenilworth, NJ, USA.

Disclosures. Rongzhe Liu, Dipen Patel, and Sakina Nanji are employees of Pharmerit - an OPEN Health Company that received funding from Merck Sharp \& Dohme Corp., a subsidiary of Merck \& Co., Inc., Kenilworth, NJ, USA to conduct the study. Adnan Alsumali, Laurence M Djatche, and Dominik Lautsch are employees of Merck Sharp \& Dohme Corp., a subsidiary of Merck \& Co., Inc., Kenilworth, NJ, USA and hold stock of Merck \& Co., Inc., Kenilworth, NJ, USA. 
Compliance with Ethics Guidelines. This study relied on published estimates from literature as analysis inputs. Therefore, ethics committee approval was not required.

Data Availability. Data sharing is not applicable to this article as no datasets were generated or analyzed during the current study.

Open Access. This article is licensed under a Creative Commons Attribution-NonCommercial 4.0 International License, which permits any non-commercial use, sharing, adaptation, distribution and reproduction in any medium or format, as long as you give appropriate credit to the original author(s) and the source, provide a link to the Creative Commons licence, and indicate if changes were made. The images or other third party material in this article are included in the article's Creative Commons licence, unless indicated otherwise in a credit line to the material. If material is not included in the article's Creative Commons licence and your intended use is not permitted by statutory regulation or exceeds the permitted use, you will need to obtain permission directly from the copyright holder. To view a copy of this licence, visit http://creativecommons.org/licenses/bync/4.0/.

\section{REFERENCES}

1. Virani SS, Alonso A, Benjamin EJ, et al. Heart disease and stroke statistics-2020 update: a report from the American Heart Association. Circulation. 2020;141(9):e139-e596.

2. Ibrahim NE, Song Y, Cannon CP, et al. Heart failure with mid-range ejection fraction: characterization of patients from the PINNACLE Registry®. ESC Heart Fail. 2019;6(4):784-92.

3. Vasan RS, Xanthakis V, Lyass A, et al. Epidemiology of left ventricular systolic dysfunction and heart failure in the Framingham study: an echocardiographic study over 3 decades. JACC Cardiovasc Imaging. 2018;11(1):1-11.

4. Ho JE, Lyass A, Lee DS, et al. Predictors of new-onset heart failure: differences in preserved versus reduced ejection fraction. Circ Heart Fail. 2013;6(2): 279-86.
5. Gurwitz JH, Magid DJ, Smith DH, et al. Contemporary prevalence and correlates of incident heart failure with preserved ejection fraction. Am J Med. 2013;126(5):393-400.

6. Gerber Y, Weston SA, Redfield MM, et al. A contemporary appraisal of the heart failure epidemic in Olmsted County, Minnesota, 2000 to 2010. JAMA Internal Med. 2015;175(6):996-1004.

7. Shah KS, Xu H, Matsouaka RA, et al. Heart failure with preserved, borderline, and reduced ejection fraction: 5-year outcomes. J Am Coll Cardiol. 2017;70(20):2476-86.

8. Armstrong PW, Pieske B, Anstrom KJ, et al. Vericiguat in patients with heart failure and reduced ejection fraction. N Engl J Med. 2020;382(20): 1883-93.

9. Butler J, Braunwald E, Gheorghiade M. Recognizing worsening chronic heart failure as an entity and an end point in clinical trials. JAMA. 2014;312(8): 789-90.

10. DeVore AD, Hammill BG, Sharma PP, et al. Inhospital worsening heart failure and associations with mortality, readmission, and healthcare utilization. J Am Heart Assoc. 2014. https://doi.org/10. 1161/JAHA.114.001088.

11. Butler J, Yang M, Manzi MA, et al. Clinical course of patients with worsening heart failure with reduced ejection fraction. J Am Coll Cardiol. 2019;73(8): 935-44.

12. Butler J, Djatche L, Sawhney B, et al. Clinical and economic burden of chronic heart failure and reduced ejection fraction following a worsening heart failure event. Adv Ther. 2020;37:4015-32.

13. Mentz RJ, Djatche L, Pulungan Z, et al. Characteristics and outcomes of heart failure with reduced ejection fraction patients enrolled in Medicare advantage with and without recent worsening heart failure. J Am Coll Cardiol. 2020;75(11 Supplement 1):809.

14. Bress AP, King JB, Brixner D, et al. Pharmacotherapy treatment patterns, outcomes, and health resource utilization among patients with heart failure with reduced ejection fraction at a US academic medical center. Pharmacotherapy. 2016;36(2):174-86.

15. Setoguchi S, Stevenson LW, Schneeweiss S. Repeated hospitalizations predict mortality in the community population with heart failure. Am Heart J. 2007;154(2):260-6.

16. Solomon SD, Dobson J, Pocock S, et al. Influence of nonfatal hospitalization for heart failure on 
subsequent mortality in patients with chronic heart failure. Circulation. 2007;116(13):1482-7.

17. Heidenreich PA, Albert NM, Allen LA, et al. Forecasting the impact of heart failure in the United States: a policy statement from the American Heart Association. Circulation. 2013;6(3):606-19.

18. Olchanski N, Vest AR, Cohen JT, et al. Comparing inpatient costs of heart failure admissions for patients with reduced and preserved ejection fraction with or without type 2 diabetes. Cardiovasc Endocrinol Metab. 2020;9(1):17.

19. Echouffo-Tcheugui JB, Bishu KG, Fonarow GC, et al. Trends in health care expenditure among US adults with heart failure: the medical expenditure panel survey 2002-2011. Am Heart J. 2017;186:63-72.

20. Butler J, Djatche LM, Sawhney B, et al. Clinical and economic burden of chronic heart failure and reduced ejection fraction following a worsening heart failure event. Adv Ther. 2020;37(9):4015-32.

21. Mentz RJ, Djatche L, Pulungan Z, et al. Characteristics and outcomes of heart failure with reduced ejection fraction patients enrolled in Medicare advantage with and without recent worsening heart failure. J Am College Cardiol. 2020;75(11 Supplement 1):809.

22. Bureau of Labor Statistics. Consumer Price Index. Medical care component 2021 [cited 2021 January 11]. Available from: https://data.bls.gov/timeseries/ CUUR0000SAM?output_view=data

23. Ezekowitz JA, O'Connor CM, Troughton RW, et al. N-terminal pro- B-type natriuretic peptide and clinical outcomes: vericiguat heart failure with reduced ejection fraction study. JACC Heart Fail. 2020;8(11):931-9.

24. IBM Micromedex. RED BOOK® 2021. http:// micromedex.com. Accessed 12 January 2021.

25. PRINIVIL [prescribing information]. Whitehouse Station, NJ: Merck \& Co., Inc. 2019.

26. COREG [prescribing information]. Research Triangle Park, NC: GlaxoSmithKline. 2017.

27. ENTRESTO [prescribing information]. East Hanover, NJ: Novartis. 2019.
28. ALDACTONE [prescribing information]. New York, NY: Pfizer Inc. 2008.

29. Sullivan SD, Mauskopf JA, Augustovski F, et al. Budget impact analysis-principles of good practice: report of the ISPOR 2012 Budget Impact Analysis Good Practice II Task Force. Value Health. 2014;17(1):5-14.

30. Borer JS, Kansal AR, Dorman ED, et al. Budget Impact of adding ivabradine to standard of care in patients with chronic systolic heart failure in the United States. J Manag Care Spec Pharm. 2016;22(9):1064-71.

31. Chan W, Deschaseaux C, Gillies H, et al. A U.S. budget impact analysis of ENTRESTO (sacubitril/valsartan) versus renin-angiotensin-aldosterone system inhibition only, for heart failure patients with reduced ejection fraction. J Manage Care Spec Pharm 22:S85-6.

32. Institute for Clinical and Economic Review. CardioMEMS ${ }^{\mathrm{TM}}$ HF system (St. Jude Medical, Inc.) and sacubitril/valsartan (Entresto ${ }^{\mathrm{TM}}$, Novartis AG) for management of congestive heart failure: effectiveness, value, and value-based price benchmarks. Final Report 2015. https://icer-review.org/wpcontent/uploads/2016/01/CHF_Final_Report_ 120115.pdf. Accessed 21 Feb 2020.

33. Benjamin EJ, Muntner P, Alonso A, et al. Heart disease and stroke statistics-2019 update: a report from the American Heart Association. Circulation. 2019;139(10):e56-528.

34. Goyal P, Almarzooq ZI, Horn EM, et al. Characteristics of hospitalizations for heart failure with preserved ejection fraction. Am J Med. 2016;129(6):635 (e15-635. e26).

35. Butler J, Djatche L, Sawhney B, et al. Real world study of characteristics and outcomes of commercially insured patients with stable versus worsening chronic heart failure with reduced ejection fraction. J Am College Cardiol. 2020;75(11 Supplement 1): 1014.

36. Obi EN, Swindle JP, Turner SJ, et al. Health care costs for patients with heart failure escalate nearly 3 -fold in final months of life. J Manag Care Spec Pharm. 2016;22(12):1446-56. 